\title{
Reading in Arabic Orthography: The influence of Short Vowels on Reading Accuracy and Comprehension of Poor and Normal Arabic Readers
}

\author{
Abedalhakeem Salfeety \& Salim Abu-Rabia \\ University of Haifa, Faculty of Education, Haifa, Mount Carmel 31905, Israel \\ Salimar@edu.haifa.ac.il
}

\begin{abstract}
Research conducted on strategies aimed at improving reading skills and comprehension among Arabic readers (Abu Rabia, 1997, 1998) reported on the contribution, of the addition of short vowels to Arabic texts, to both the acquisition of proper reading skills during early childhood, and to better reading comprehension among all ages. The findings were considered controversial. Such a determination can have important implications for both local and national educational policies seeking the improvement of reading skills and comprehension among Arabic readers of all ages.

In this study, 60 native Arabic speakers, 12 years old were sampled from school in northern Israel. They were divided into two equal groups of 30 normal and 30 poor readers, based on their average grade point average in the Arabic Language subject.

The results indicated that the vocalization of Arabic texts significantly improved both reading accuracy and comprehension among all participants, whether normal or weaker readers. Further, despite the very noticeable difference between reading abilities among the two groups (regular and weak readers) at the outset, on the average we found that the addition of short vowels helped both groups acquire basic reading skills. The findings indicated that the use of vocalized texts helps readers achieve higher reading comprehension levels among all types of readers.
\end{abstract}

Keywords: Short Arabic vowels; poor readers; normal readers; Arabic texts; Phonology; vocalization of Arabic texts,

\section{Council for Innovative Research}

Journal: Journal of Advances in Linguistics

Vol .5 No 3

editor@cirjal.com

www.cirjal.com, www.cirworld.com 


\section{Literature Review}

Reading Comprehension and Short Vowels - Vocalization provides orthographic and phonological information (Bentin 1997; Shimron, 1999) that clarifies the meaning of individual words, thereby helping with their unequivocal identification (Shimron, 1997). Research done regarding the relationship between vocalization and the addition of short vowels and reading comprehension can be divided into three different types: how short vowels contributed to reading comprehension among all age levels and to the acquisition of reading skills, how they contributed to the reading skills of normal readers only, and how they failed to contribute to the level of reading comprehension.

Vocalized word contains additional information that makes its phonological processing easier (Shimron, 1989; Abu-Rabia, 1998). When such homographic words appear individually, one can only guess their meaning, but when presented in a text, they are more easily understood because of contextual hints. Therefore, reading texts without short vowels is usually not a problem (Shimron, 1989). In Arabic, the number of homographic words is relatively large, so vocalization would be ostensibly very important when reading a text made up of several words (Abu Rabia, 1997, 1998).

However, the contribution of vocalization to reading is less clear regarding non-homographic words. Vocalization of these words adds signs that the brain and eye work to decode, which may actually slow down the reading process. However short vowels may ease the creation of the phonological pattern easier. Assuming that the translation of letters into phonemes concentrates the identity of words in the phonological memory, it is likely that adding vowel signs would make a positive contribution to the interpretation of such isolated words, making them easier to remember in the short term, unti the entire sentence is understood properly (Shimron, 1989). In research literature, therefore, one can find several studies that deal with both the contribution, and lack thereof, of short vowels to reading comprehension.

The Contribution of Vowels: A number of studies in this field dealt with the contribution of vocalization in reading Arabic. The work of Abu Rabia (1996), for example, examined the contribution of short vowels and context to the identification of words in orthographic Arabic among highly skilled 18-year-old high school students. Each participant was asked to read out loud separate segments of texts and a list of words with or without short vowels. The findings clearly showed that both vocalization and context contributed positively to the participants' reading accuracy.

In 1997, Abu-Rabia examined whether the results of his previous study would be duplicable among weak readers, classified as such if they could read 45 or less vocalized words out of 100 , and skilled readers who were defined as those who succeeded in reading at least 50 words correctly. The findings of this study indeed confirmed that both short vowels and the sentence context significantly eased reading accuracy among both the weak and skilled readers. That same year, Abu Rabia conducted another study where he tried to examine the contribution of short vowels and context on different textual types, like literary texts, newspapers, and isolated words, which were all presented to participants in both vocalized and non-vocalized forms. This time, the participants were adult readers of Arabic, both weak and skilled. Here also reading of texts by both groups was improved by context and the addition of short vowels. In 1998, Abu Rabia conducted the same test among $11^{\text {th }}$ grade Arabic readers, both weak and skilled, who were asked to read texts written in a wide range of writing styles, like poetry, stories, simple texts and parts of the Koran.

Other studies examined the contribution of the addition of short vowels to Hebrew texts. Similar to Abu-Rabia's findings regarding skilled and weak readers of Arabic of all ages, Shimron (1999) achieved the same results among parallel groups of weak and strong readers of Hebrew. Among $6^{\text {th }}$ and $3^{\text {rd }}$ grade readers of Hebrew, it was found that vocalization of texts helped the older more than younger students in reading comprehension and accuracy, again demonstrating the importance of vocalization when reading different types of texts, at various levels of reading difficulty.

To further test these results, Abu Rabia (1999) conducted another study among bi-lingual Arabic speaking university students, that is, fluent speakers of both Arabic and Hebrew. Again, like all the other studies, the findings of this study showed that vocalization and short vowels indeed contributed significantly to reading comprehension and accuracy in both Arabic and Hebrew.

Further reinforcement came from yet another study conducted by Abu-Rabia in 2001, among Arab adults (22-30 years of age), whose mother tongue was Arabic and Hebrew was their second language. The findings of this study showed that both reading aloud and to oneself was improved by using the vocalized texts.

We may therefore ostensibly conclude that vocalization contributes to reading comprehension and accuracy among all ages of both Arabic and Hebrew speakers of varying reading skills.

Other Research Studies: Nonetheless, there are those that openly dispute the findings of Abu Rabia and Shimron. Frost (1994), argued that reading without short vowels is actually easier, and that practical experience shows that learning reading without short vowels from the beginning is easier for all students. Even (1995), examined the contribution of vocalization to $2^{\text {nd }}$ and $4^{\text {th }}$ grade Arab children, and found no significant difference between vocalized and non-vocalized text comprehension at these ages. A similar result was found in the research of Ravid \& Schlesinger (2001), who examined the impact of the removal of short vowels in modern Hebrew. One hundred (100) students from grades 5 , 7,9 and 11 as well as a group of adults participated in their study. Participants were asked to read aloud the same words twice, once with short vowels and once without. The findings showed that children and youths up to grade 9 tended to 
ignore the fact that the short vowels were available as part of the research stimuli. That is to say, they pronounced the words by drawing out their phonological form as if they were reading an un-vocalized text.

In contrast to those studies, the research literature includes several studies that indicate that short vowels are not helpful to skilled readers only. The study of Nahmani-Ronen (2000), examined the contribution of short vowels to beginning readers, and found that vocalization did not improve their reading comprehension. The findings of Shimron (1999) and Horowitz (1994), which examined the impact of vocalization on reading comprehension, also showed that only skilled readers are capable of utilizing phonological hints in texts and in deriving benefit from the phonological information provided by short vowels. Similar results were also attained by the research team of Shimron and Sivan (1994), which indicated that vocalization contributes to reading comprehension among skilled readers only.

\section{Short Vowels and Context in Reading Arabic: Empirical Studies}

Reviewing the literature on Arabic orthography, particularly its short short vowels, in relation to the reading process, reveals a narrow range of research done in this area, Abu Rabia being the only researcher to comprehensively investigate Arabic orthography and the use of short vowels in relation to the reading process in eight consecutive studies (1995, 1996, 1997a, 1997b, 1997c, 1998, 1999, 2001) that can be organized chronologically. Abu Rabia conducted different experiments to investigate the effect on reading comprehension and accuracy of Arabic short vowels alone, as well as in combination with other factors such as context, reading skill-levels, and text types: narratives, stories, Koranic, and poetry

Each study found that the use of short vowels in Arabic texts significantly helped readers, of all ages and levels of reading skills, improve their reading accuracy and comprehension. In fact, each study was basically conducted to further test and either confirm or refute previous studies, and in each case, the unequivocal results were positive.

In 2006, Abu Rabia teamed up with Taha in order to test the spelling development of native Arab students in grades 1 to 9 , and found that the rate of phonological errors reached $50 \%$ of all error types among all ages. This was to show the important role played by the phonology of the Arabic orthography in spelling, and that the phonological stage in reading and spelling development is continuous and lifelong even for highly skilled readers.

Continuing with the same research line, in 2007, Abu-Rabia tested the influence of morphological factors and phonological factors among grade 3, 6, 9 and 12, and revealed that morphological as well as phonological factors are good facilitators of reading among all readers and ages. This finding was explained by using evidence that showed that phonology is very hard to master by native Arabic readers who rely on visual orthographic features to facilitate reading. Similar results were obtained by Mohamed et al., (2010) and Taouk and Coltheart (2004).

Finally, in 2008, Abu Rabia together with Saliba tested the effect of phonological patterns and roots on the reading of native Arabic readers, both regular and dyslexic. The results revealed that phonological patterns were very hard for the young regular, as well as dyslexic readers, to master. The native Arabic speakers better mastered the roots of words which facilitated their word recognition.

This body of research leads to the conclusion that short vowels and context play significant roles in the reading process of Arabic:

1. They play a necessary and indispensable role in the reading accuracy of isolated words, and contribute to reading accuracy and comprehension when connected texts are read.

2. Context contributes significantly to all ages of both skilled and poor readers of Arabic.

\section{The Nature of the Arabic Language}

Classic Arabic is considered the main representative of the south-Central Semitic language group. It is the language of the Koran, the sacred book of Islam, and is therefore the religious language of all Arabic speaking Muslims. It is spoken in North Africa, the Arabian Peninsula, and other parts of the Middle East. Classic Arabic is uniform throughout the Arab world. As Kristeva (1989) put it a consensus exists among specialists in the field of Arab culture regarding the importance attributed to language in the Arab civilization. The Koran, requires that one know how to decipher and pronounce correctly the Classic Arabic language in order to gain access to its teachings.

Arabic has a number of dialects, all of which have been strongly influenced by the literary language. Speakers of dialects use modern literary Arabic, a modified form of classical Arabic, the language of the Koran, as a formal spoken and written language, instead of the local vernacular dialects. They use modern Literary Arabic for "communication with speakers of other Arabic dialects for formal speeches, formal documents, literary works, whereas the local dialect is used primarily for ordinary oral communication and for popular literature (Lyovin, 1997,p.201). The spread of literacy and the increase in higher education in the Arab world, have contributed to the growth in influence of Classical Arabic.

\section{The Morphology of Arabic}

An Arabic word is composed of two parts: (1) the root, which generally consists of three consonants, and which provides the basic lexical meaning of the world, and (2) the pattern, which consists of short vowels. The vowels give grammatical meaning to the word. The language also makes use of prefixes and suffixes, which act as subject markers, pronouns, prepositions, and the definite article. Verbs in Arabic are regular in conjugation. There are two tenses: the perfect, formed by the addition of suffixes, which is often used to express past time; and the imperfect, formed by the addition of prefixes and sometimes containing suffixes indicating number and gender, which is often used for expressing present or future 
time, In addition to the two tenses there are imperative forms, an active participle. a passive participle, and a verbal noun. Verbs are inflected for three persons, three numbers (singular, dual, plural), and two genders. In Classical Arabic there is no dual form and no gender differentiation in the first person, and the modern dialects have lost all dual forms. The classical language also has forms for the passive voice. There are three cases (nominative, genitive, and accusative) in the declensional system of Classical Arabic nouns; nouns are no longer declined in the modern dialects. Pronouns occur both as suffixes and as independent words.

\section{Features of Arabic Script: Short vowels/Diacritics}

Arabic is read and written from right to left in a cursive consonantal script based on 25 consonant symbols plus six short

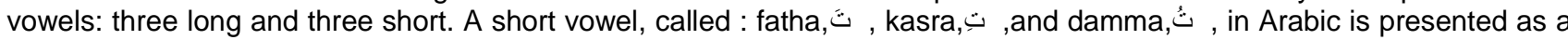
mark above or below an adjoining consonant. If vocalized, its orthography is considered transparent, in which the correspondence between graphemes to phonemes is consistent; otherwise it is considered a deep orthography. The script is also distinguished by the large number of ligatures and by the different shapes its characters take; depending on their positions in a text string and the surrounding characters, these letters take up to four different allographs: independent, word- initial, medial, and final, e.g., the letter,ح:ح and بحر , حب , respectively. There is no cursive versus "

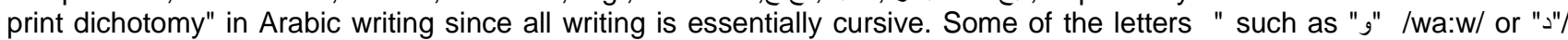

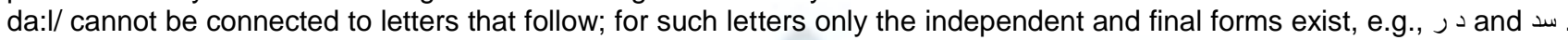
Unlike English, written Arabic has no equivalent to capital letters, and characters can be joined to form ligatures. Additional signs are used in Arabic script such as tanwin or nunation which express the indefinite for Arabic nouns, e.g., the addition of ending-un, marked as _ superscript in the nominative case change to - /-an/and-/-in/ in the " oblique cases." For example, the word, 'town' is written:مدينة: madinatun (nominative case); مدينة madinain (genitive case) (Campbell, 1997). Sukun, or resting, is another sign that takes the superscript marker over a consonant and indicates that the consonant is voweless: e.g., شرق : ' east' where the consonant ,, , is marked by sukun,' Two types of hamza exist in Arabic, hamzat-al-qat' or the cutting hamza, e.g., l ; and hamzat-al-wasl or the joining hamza, e.g., 1

The first one is " pure glottal stop with full consonantal value and in well-edited books and periodicals is generally written" (Cowan, 1958, p.6). Hamzat-al-qat' is rule governed, especially when it is the first radical in a verb. The initial hamza, always, is carried by an alif, with fatha. Kasra or damma as required, e.g., or ! . medial hamza may be carried by alif, waw or ya, e.g., I , ' oris ; and the final hamza wich is placed on the line of script, e.g., \&. Hamza-al-wasl on the other hand, takes the form, "I", and " always occurs at the beginning of a word and its vowel is written above or below 'alif, e.g., I or i, or $!$. if any word precedes it, hamzat-al-wasl, and its vowel must be elided. It is not actually written although we sometimes find it written as $\_$. Modern opinion, however, does not approve of this use of $f_{\varepsilon}$, which is reserved for hamzatal-qat', "I" (Cowan, 1958, p. 6). Shaddah (tashdid) or strengthening, "", is a mark written above the letter to indicate a doubled consonant ( geminated), e.g., كسر : ' ' he smashed to pieces.' When two alifs ( and one of them is the " bearer" of hamzat-al-qat') come together," madda or lengthrning, a superscript sign in the form, , written along an alif, will replace the two alifs, e.g., i . (Campbell, 1997,p. 2- 3).

The structure of the Arabic syllable, as Bateson (1967) described, is expressed in terms of consonants and short vowels: All Arabic syllables must begin with a single consonant; the simplest type is CV,a consonant plus a short vowel, e.g., /huwa/ هو ' شرب he,' / shariba/ drank,' with two and three short syllables respectively. A long syllable either contains a long vowel, CV, or has the form CVC where another syllable with its own initial consonant follow. For example, /qable/ قبلي ' before me' has a first syllable of the type of CvC ( qab-) and a second syllable Cv (-li) .... Syllables of the type CvC are termed "overlong" and rarely occur .... On the whole, syllable formation is very regular in Arabic. (Bateson, 1967).

\section{Research Questions}

1-How do short vowels influence the accuracy of reading and comprehension among normal readers?

2-How do short vowels influence the fluency of reading among regular and poor readers?

3- How do short vowels influence the accuracy of reading and comprehension among poor readers?

\section{Research Assumptions:}

1. Short vowels will increase the level of reading accuracy among both normal and poor readers.

2. Short vowels will increase the level of reading comprehension among both normal and poor readers.

3. Short vowels will increase reading fluency among both normal and weak readers.

\section{Method}

\section{Research Tools}

\section{Screening Tools}

a) Initial Screening Test: The reading comprehension text was a one-page text on poverty taken from the $7^{\text {th }}$ grade curriculum list (Abu Fannah, 1985). Ten multiple choice questions were asked about each text, and the pupils had to choose the correct answer out of four possible answers for each question. 
The questions were classified according to difficulty. The text was not seen or taught by the pupils beforehand. All 150 pupils in the $7^{\text {th }}$ grade took the test.

b) Phonological Skill Test: The list was divided into two pages, with the first page including 20 words (Abu Fanneh, 1985). The lists of words was arranged according to linguistic difficulty, from easy to difficult. The second page contained phonemes (1-7), and the pupils had to count the number of phonemes in each word. The test was taken by the 150 pupils in grade 7 .

c) List of Isolated Words: A two page list was used. The first page contained 20 words (Eladaseh, 2008). The list of words was arranged according to linguistic difficulty, from easy to difficult. On the second page there were two signs: $(+)$ indicating correct reading of words, and (-) which indicated that the reading was incorrect. The test was given to 60 pupils, 30 poor and 30 regular readers.

\section{Experimental Tools}

A) Comprehension Test: Four (4) familiar stories followed by 10 multiple choice questions about each story were used for the comprehension test. The texts related to social problems and their possible solutions. The focus of stories was the importance of social values like justice, responsibility toward the community, equality, discrimination and belonging. Each story was approximately one page long and taken from the school curriculum. The stories were followed by several multiple choice questions, ranging from easy to difficult. The test was given to 60 pupils, 30 poor and 30 regular readers.

\section{B) Accuracy and Fluency in Reading Test:}

Two lists of words taken from the school curriculum were used. One list with full vocalization included 40 words (Abu Fanneh , 1985). The second list had the same words un-vocalized. Two signs were used: $(+)$ which indicated correct reading and (-) which indicated incorrect reading were on the pages. A third page was used to assess fluency which was measured by recording the time it took each student to read all words. The lists were composed according to increased levels of difficulty.

All participants, whether regular or weak readers, were required to individually read all lists aloud inside a quiet room in the school. The reading was recorded and response time was documented to check accuracy.

Increased levels of difficulty - number of phonemes: The more phonemes the word contained, the more difficult it was considered to be. The words were also evaluated by experts in the Arabic language who were asked to rate them according to their frequency of occurrence in the Arabic language curriculum.. The more frequent the occurrence of a word in the National Arabic Language Curriculum the less difficult it was considered.

\section{The Research Procedure}

Two tests, The Phenomenological Skill Test and The Initial Screening Test were administered by class teachers, and the results were collected and scored by the research team in order to form two groups of thirty pupils each. One group had thirty low scoring readers and the second group had 30 normal scoring readers.

Two days later the two groups of thirty pupils took the List of Isolated Words test in two quiet rooms in the school: the library and a laboratory room. This test was administered individually and response times and the accuracy of reading were recorded.

During the following step the reading comprehension test with short vowels was administered. Two days later, the reading comprehension test without. short vowels was administered. The pupils were then divided into two mixed groups of 15 normal and 15 weak readers.

Finally, a week later, the reading accuracy and fluency tests were administered, and response times and accuracy of reading were recorded.

\section{Results}

\section{Statistical analysis}

The data was analyzed and hypotheses were tested using the following tests which were part of the SPSS statistical package:

1. The MANOVA multi-variable analysis test was performed in order to check main effects and interactions between one or more independent variables measured on a nominal scale, and two or more dependent variables measured on a numerical scale (first assumption).

2. The Pearson test was performed in order to evaluate co-relations between the nominal and numerical scale variables (second assumption).

3. A Linear Regression was performed in order to predict numerical scale variable (third assumption). 
Two groups of pupils were formed based on their tested reading and reading comprehension scores, a group of 30 normal readers and a group of 30 poor readers. A significant difference between the two groups was found. in reading accuracy and reading comprehension of texts. Following the allocation of students to the two groups based on the test scores the students' teachers were consulted in order to validate the creation of the two groups. The test results and the teachers' evaluation of student capabilities in reading and reading comprehension were found to be equivalent.

The first assumption was: Short vowels will increase the level of reading accuracy among both normal and poor readers:

Statistically, this assumption was fully confirmed. In terms of reading comprehension with and without short vowels, and reading fluency with and without short vowels, we found direct connections between reading accuracy with and without short vowels and reading comprehension with and without short vowels and reading fluency/word processing with and without short vowels. It was found that in the vocalized texts, normal readers showed higher understanding than poor readers: $p<0.01, F(1.58)=251.7$, and $p<0.01 F(1.58)=342.8$ respectively.

Likewise, in non-vocalized texts, regular readers showed much greater comprehension than poor ones: $p<0.01, F(1.58)$ $=369.75$, and $p<0.01 F(1.58)=311.54$ respectively.

It was also found that regular readers showed higher levels of accuracy in reading words with and without short vowels as opposed to poor readers in reading word accuracy with and without short vowels: $p<0.01, F(1.58)=247.22$, and $p<$ $0.01 \mathrm{~F}(1.58)=244.48$ respectively

Finally, it was found that normal readers showed greater reading fluency in reading words with and without short vowels as opposed to poor readers in their reading fluency with and without short vowels.

\section{Table 1: Means and Standard Deviations Among all Readers' type}

\begin{tabular}{lllllllll}
\hline & Text 1. & Text 2. & Text 1. & Text 2 & R.A.W.W.V1 & R.A.W.W.V2 & RFW & RF \\
& V.R.C & V.R.C & N.V.R.C & N.V.R.C & & & & \\
\hline Normal & 83.66 & 83.33 & 76.66 & 76.33 & 84.00 & 76.10 & .33 & .42 \\
Reader & $(6.68)$ & $(8.02)$ & $(8.02)$ & $(7.64)$ & $(7.11)$ & $(6.08)$ & $(0.09)$ & $(0.06)$ \\
Poor & 51.00 & 50.33 & 33.33 & 34.00 & 41.50 & 34.90 & 1.11 & 1.38 \\
Reader & $(6.07)$ & $(8.08)$ & $(10.61)$ & $(9.32)$ & $(13.07)$ & $(12.99)$ & $(0.40)$ & $(0.17)$ \\
\hline
\end{tabular}

V.R.C= Vocalized Reading Comp N.V.R.C= Non-vocalized Read. Comp.

R.A.W.W.V1= Reading Accuracy- Words with short vowels

R.A.W.W.V2= Reading Accuracy- Words with short vowels

RFW= Reading Fluency- Words with short vowels

RF= Reading Fluency- Words without short vowels

Table 2: Means and Standard Deviations of Normal and Poor Readers on All Tests

\begin{tabular}{cccccccc}
\hline Dependent Variable & $\begin{array}{c}\text { Type of } \\
\text { Reader }\end{array}$ & Mean & $\begin{array}{c}\text { Standard } \\
\text { Deviation }\end{array}$ & SS & MS & F & P \\
\hline Text 1 Vocalized & $\mathbf{N}$ & 83.66 & 6.68 & 16335.00 & 16335.00 & 342.85 & .000 \\
Reading Comp. & $\mathbf{P}$ & 51.00 & 6.07 & & & & \\
Text 2 Vocalized & $\mathbf{N}$ & 83.33 & 8.02 & 16335.00 & 16335.00 & 251.75 & .000 \\
Reading Comp. & $\mathbf{P}$ & 50.33 & 8.08 & & & & \\
Text 1 Non-vocalized & $\mathbf{N}$ & 76.66 & 8.02 & 27735.00 & 27735.00 & 311.54 & .000 \\
Reading Comp. & $\mathbf{P}$ & 33.33 & 10.61 & & & & \\
Text 2 Non-vocalized & $\mathbf{N}$ & 76.33 & 7.64 & 26881.66 & 26881.66 & 369.75 & .000 \\
Reading Comp. & $\mathbf{P}$ & 34.00 & 9.32 & & & & \\
Reading Accuracy- & $\mathbf{N}$ & 84.00 & 7.11 & & & & \\
Words with short & $\mathbf{P}$ & 41.50 & 13.07 & 27093.75 & 27093.75 & 244.48 & .000 \\
vowels & $\mathbf{N}$ & 76.10 & 6.08 & & & & \\
Reading Accuracy- & $\mathbf{N}$ & & & & & \\
Words without short & $\mathbf{P}$ & 34.90 & 12.99 & 25461.600 & 25461.60 & 247.22 & .000 \\
$\quad$ vowels & $\mathbf{N}$ & .3350 & .09 & & & & \\
Fluency-Words with & $\mathbf{P}$ & 1.11 & .40 & 9.00 & 9.00 & 102.11 & .000 \\
short vowels & $\mathbf{N}$ & .42 & .06 & & & & \\
Fluency-Words without & $\mathbf{P}$ & 1.38 & .17 & 13.90 & 13.90 & 796.32 & .000 \\
short vowels & $\mathbf{P}$ & & & & & &
\end{tabular}


(df $(\mathrm{N}=\mathbf{3 0} \quad)$

Second Assumption: Short vowels will increase the level of reading comprehension among both normal and poor readers: Here we examined whether there is any connection between reading comprehension (texts $1+2)$ with and without short vowels, reading accuracy with and without short vowels, and reading fluency with and without short vowels, among normal and poor readers. As we can see, this assumption was also confirmed in full. In order to reach this conclusion, Pearson tests were performed.

It was found that a significant and positive connections existed between both high and medium readers and the conditions of reading comprehension (text 1 or 2, vocalized and non-vocalized) and word reading accuracy (with or without short vowels)

We also found significant and negative connections of high and medium readers between the factors of reading comprehension (text 1 or 2, vocalized and non-vocalized) and word reading fluency (with or without short vowels).

Among poor readers we found significant and positive correlations between high and medium intensity between the conditions of reading comprehension of non-vocalized texts (1 or 2 ) and word reading accuracy (with or without short vowels).

Also found was a significant positive connection of medium intensity between reading comprehension of non-vocalized text no. 1 and reading fluency of words with short vowels, $P<0.001 \mathrm{r}=0.5$.

Finally, a significant negative correlation of medium intensity was found between reading comprehension of non-vocalized text 2 and reading fluency of words with short vowels.

Table 3: Pearson Correlations Matrix of All Variables Among Normal Readers $(\mathrm{N}=30)$

\begin{tabular}{|c|c|c|c|c|c|c|c|c|}
\hline & $\begin{array}{l}\text { Reading } \\
\text { Comp. } \\
\text { Text } 1 \text { - } \\
\text { Vocalized }\end{array}$ & $\begin{array}{l}\text { Reading } \\
\text { Comp. } \\
\text { Text } 2 \text { - } \\
\text { Vocalized }\end{array}$ & $\begin{array}{l}\text { Reading } \\
\text { Comp. } \\
\text { Text } 1 \text { - } \\
\text { Non- } \\
\text { Vocalized }\end{array}$ & $\begin{array}{l}\text { Reading } \\
\text { Comp. } \\
\text { Text } 2 \text { - } \\
\text { Non- } \\
\text { Vocalized }\end{array}$ & $\begin{array}{l}\text { Reading } \\
\text { Accuracy } \\
\text {-Words } \\
\text { with } \\
\text { Short } \\
\text { vowels }\end{array}$ & $\begin{array}{l}\text { Reading } \\
\text { Accuracy } \\
\text { - Words } \\
\text { without } \\
\text { Short } \\
\text { vowels }\end{array}$ & $\begin{array}{l}\text { Reading } \\
\text { Fluency } \\
\text { of } \\
\text { Words } \\
\text { with } \\
\text { Short } \\
\text { vowels }\end{array}$ & $\begin{array}{l}\text { Reading } \\
\text { Fluency } \\
\text { of Words } \\
\text { without } \\
\text { Short } \\
\text { vowels }\end{array}$ \\
\hline $\begin{array}{l}\text { Reading } \\
\text { Comp. } \\
\text { Text } 1 \text { - } \\
\text { Vocalized }\end{array}$ & -- & $0.645^{\star * \star}$ & $0.580^{*}$ & $0.486^{*}$ & -- & $0.550^{*}$ & $0.506^{*}-$ & -- \\
\hline $\begin{array}{l}\text { Reading } \\
\text { Comp. } \\
\text { Text } 2 \text { - } \\
\text { Vocalized }\end{array}$ & $0.645^{\star * \star}$ & -- & $0.407^{*}$ & $0.712^{* \star *}$ & $0.543^{*}$ & $0.664^{* \star *}$ & $0.475^{\star}-$ & $0.630^{* \star *}-$ \\
\hline $\begin{array}{l}\text { Reading } \\
\text { Comp. } \\
\text { Text } 1 \text { - } \\
\text { Non- } \\
\text { Vocalized }\end{array}$ & $0.580^{*}$ & $0.407^{*}$ & 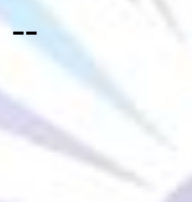 & $0.500^{*}$ & & $0.646^{\star * *}$ & -- & $-0.599^{* \star *}$ \\
\hline $\begin{array}{l}\text { Reading } \\
\text { Comp. } \\
\text { Text } 2 \text { - } \\
\text { Non- } \\
\text { Vocalized }\end{array}$ & $0.486^{*}$ & $0.712^{\star \star \star}$ & $0.500^{*}$ & -- & $0.500^{*}$ & $0.846^{\star * \star}$ & $-0.366^{\star}$ & $-0.852^{* \star \star}$ \\
\hline $\begin{array}{l}\text { Reading } \\
\text { Accuracy } \\
\text {-Words } \\
\text { with } \\
\text { Short } \\
\text { vowels }\end{array}$ & -- & $0.543^{*}$ & -- & $0.500^{*}$ & -- & $0.735^{\star \star *}$ & $-\overline{0.736^{\star \star *}}$ & $-0.755^{\star \star \star}$ \\
\hline $\begin{array}{l}\text { Reading } \\
\text { Accuracy } \\
\text { - Words } \\
\text { without } \\
\text { Short }\end{array}$ & $0.550^{*}$ & $0.664^{* * *}$ & $0.646^{* * *}$ & $0.846^{* * *}$ & $0.735^{\star \star \star}$ & -- & $-0.466^{*}$ & $-0.971^{\star \star \star}$ \\
\hline
\end{tabular}


vowels Reading Fluency of Words with Short vowels

Reading $0.630^{* * *}--0.599^{\star * *}-0.852^{* * *}$ $-0.755^{\star \star *}$ $-0.971^{* * *}$

Fluency of Words without

Short vowels

\section{$\mathrm{p}<0.05^{*}, \mathrm{p}<0.01^{* *}, \mathrm{p}<0.001$}

Table 4: Pearson Correlations Matrix of All Variables Among Poor Readers $(\mathbf{N}=\mathbf{3 0})$

\begin{tabular}{|c|c|c|c|c|c|c|c|c|}
\hline & $\begin{array}{l}\text { Reading } \\
\text { Comp. } \\
\text { Text } 1- \\
\text { Vocalized }\end{array}$ & $\begin{array}{l}\text { Reading } \\
\text { Comp. } \\
\text { Text } 2 \text { - } \\
\text { Vocalized }\end{array}$ & $\begin{array}{l}\text { Reading } \\
\text { Comp. } \\
\text { Text } 1 \text { - } \\
\text { Non- } \\
\text { Vocalized }\end{array}$ & $\begin{array}{l}\text { Reading } \\
\text { Comp. } \\
\text { Text 2- } \\
\text { Non- } \\
\text { Vocalized }\end{array}$ & $\begin{array}{l}\text { Reading } \\
\text { Accuracy } \\
\text {-Words } \\
\text { with } \\
\text { Short } \\
\text { vowels }\end{array}$ & $\begin{array}{l}\text { Reading } \\
\text { Accuracy } \\
\text { - Words } \\
\text { without } \\
\text { Short } \\
\text { vowels }\end{array}$ & $\begin{array}{l}\text { Reading } \\
\text { Fluency of } \\
\text { Words } \\
\text { with Short } \\
\text { vowels }\end{array}$ & $\begin{array}{l}\text { Reading } \\
\text { Fluency } \\
\text { of Words } \\
\text { without } \\
\text { Short } \\
\text { vowels }\end{array}$ \\
\hline $\begin{array}{l}\text { Reading } \\
\text { Comp. Text } 1 \\
\text { - Vocalized }\end{array}$ & -- & & & & -- & -- & -- & -- \\
\hline $\begin{array}{l}\text { Reading } \\
\text { Comp. Text } 2 \\
\text { - Vocalized }\end{array}$ & $0.572^{\star \star *}$ & -- & & & -- & -- & -- & -- \\
\hline $\begin{array}{l}\text { Reading } \\
\text { Comp. Text } 1 \\
\text { - Non- } \\
\text { Vocalized }\end{array}$ & $0.470^{*}$ & $0.429^{*}$ & -- & & & & & -- \\
\hline $\begin{array}{l}\text { Reading } \\
\text { Comp. Text } 2 \\
\text { - Non- } \\
\text { Vocalized }\end{array}$ & $0.531^{*}$ & $0.439^{*}$ & $0.732^{* * *}$ & -- & & & 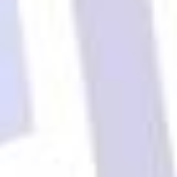 & -- \\
\hline $\begin{array}{l}\text { Reading } \\
\text { Accuracy - } \\
\text { Words with } \\
\text { Short vowels }\end{array}$ & -- & & $0.559^{*}$ & $0.444^{*}$ & & & & -- \\
\hline $\begin{array}{l}\text { Reading } \\
\text { Accuracy - } \\
\text { Words } \\
\text { without Short } \\
\text { vowels }\end{array}$ & -- & -- & $0.685^{\star * *}$ & $0.544^{*}$ & $0.801^{* * *}$ & & & -- \\
\hline $\begin{array}{l}\text { Reading } \\
\text { Fluency of } \\
\text { Words with } \\
\text { Short vowels }\end{array}$ & -- & -- & $0.414^{*}$ & $-0.433^{*}$ & $-\overline{0.830 * \star *}$ & $-0.604^{\star * *}$ & -- & -- \\
\hline $\begin{array}{l}\text { Reading } \\
\text { Fluency of } \\
\text { Words } \\
\text { without Short } \\
\text { vowels }\end{array}$ & -- & -- & -- & -- & -- & -- & -- & -- \\
\hline
\end{tabular}




\section{$\mathrm{p}<0.05^{*}, \mathrm{p}<0.01^{* *}, \mathrm{p}<0.001^{* * *}$}

Third assumption: Short vowels will catalyze the speed of word processing (reading fluency) among both normal and weak readers. Assumption 3 assumes that one can predict reading comprehension (texts $1+2$ ) with and without short vowels for both normal and poor readers, based on how fast a person can read words - reading fluency - with and without short vowels. Therefore, first and foremost, regarding the very essence of the assumption, it was fully confirmed and indeed, vocalization helps speed up the identification /process of words (reading fluency).

As to the possibility of predicting reading comprehension based on reading accuracy and fluency, a linear regressive analysis based on the Enter method was used. In Tables 5 and 6 below the results of the regression are presented for normal and poor readers respectively.

We can see that among normal readers, based on the independent variables of reading accuracy and words with and without short vowels, the level of reading comprehension can be predicted. The results indicate that reading comprehension can be predicted on the basis of the reader's ability to identify and express individual words with or without short vowels and read words accurately, as well as how capable the individual is in reading word fluency tests. This relationship was found when non-vocalized texts were used.

Specifically, we found that::

An increase of one unit in word reading accuracy will increase reading comprehension of vocalized text 1 by 0.89 units (percentage of explained diversity $-34 \%$ ), while an increase of one unit in word fluency without short vowels will lower reading comprehension of vocalized text 1 by 56.13 units (percentage of explained diversity 25.8\%). No significant influence of reading accuracy and fluency of vocalized words was found on reading comprehension in the vocalized text 1.

An increase of one unit in reading accuracy of non-vocalized words will increase reading comprehension of vocalized text 2 by 0.76 units (percentage of explained diversity $44.8 \%$ ), while an increase of one unit in word fluency without short vowels will lower reading comprehension of vocalized text 2 by 68.01 units (percentage of explained diversity $43.6 \%$ ). No significant impact of reading accuracy and word fluency with short vowels on reading comprehension in a vocalized text 2.

An increase of one unit in word reading accuracy without short vowels increases the reading comprehension of unvocalized text 1 by 1.24 units (percentage of explained diversity $48.8 \%$ ) in un-vocalized text 1 , while an increase of one unit in word fluency without short vowels will lower reading comprehension in an un-vocalized text 1 by 85.66 units (percentage of explained diversity $36.8 \%$ ). No significant impact of reading accuracy and word fluency was found on reading comprehension of an un-vocalized text 1.

An increase of one unit of word reading accuracy without short vowels will increase reading comprehension of unvocalized text 2 by 1.31 units (percentage of explained diversity $74.7 \%$ ), while an increase of one unit in reading fluency without short vowels will lower reading comprehension in a vocalized text 1 by 108.81 units (percentage of explained diversity $72.9 \%$ ). No significant impact of reading accuracy and word fluency with short vowels was found on reading comprehension in an un-vocalized text 2.

Among poor readers, based on the independent variables of reading accuracy and words with and without short vowels, one can predict the level of reading comprehension: An increase of one unit in word reading accuracy without short vowels will increase reading comprehension in vocalized text 1 by 0.33 units (percentage of explained variance $15.5 \%$ ). No significant impact of reading accuracy and word fluency (with or without short vowels) was found on reading comprehension of a vocalized text 1 .

\section{Table 5: Linear Regression that Predicts Reading Achievements of Normal Readers}

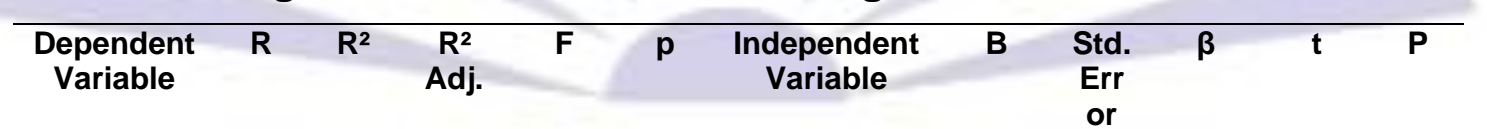

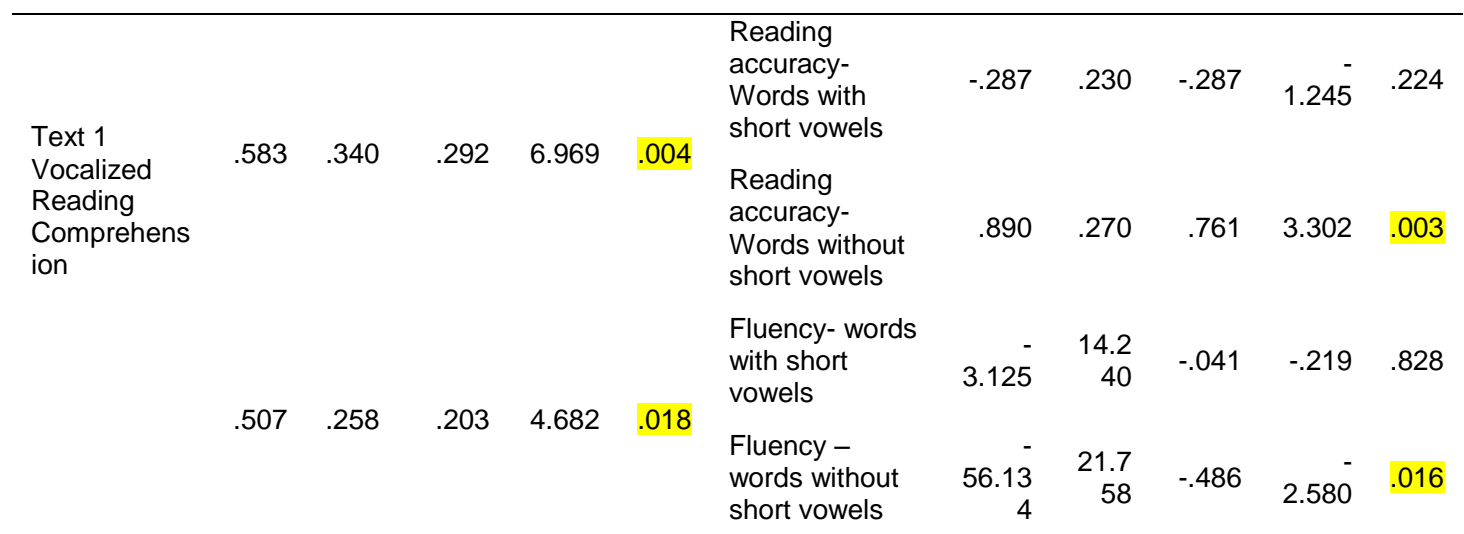




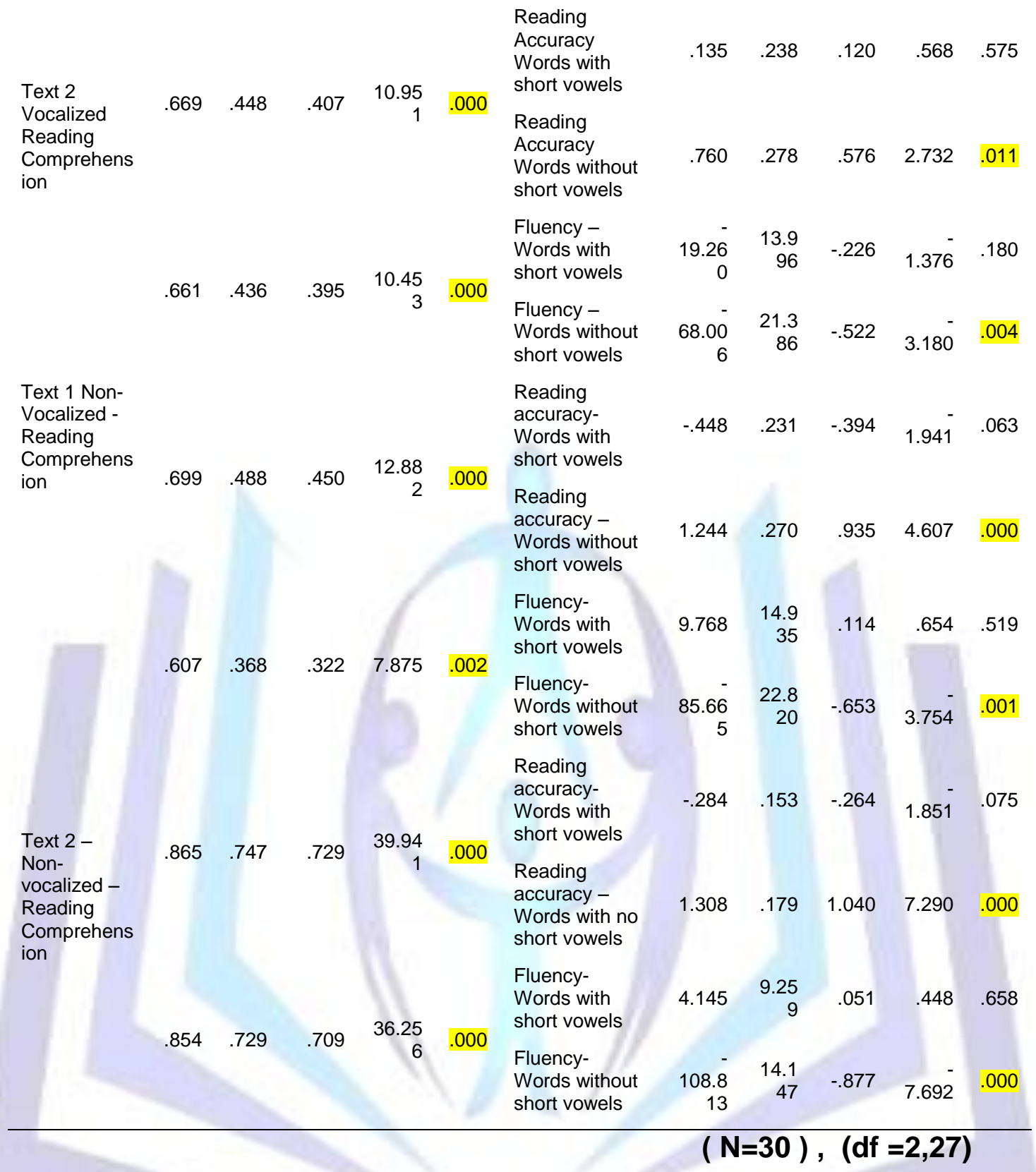

Table 6: Linear Regression that Predicts Reading Comprehension Achievements in Poor Readers

\begin{tabular}{|c|c|c|c|c|c|c|c|c|c|c|c|}
\hline $\begin{array}{l}\text { Dependent } \\
\text { Variable }\end{array}$ & $\mathbf{R}$ & $\mathbf{R}^{2}$ & $\mathrm{R}^{2}$ Adj. & $F$ & $p$ & $\begin{array}{c}\text { Independent } \\
\text { Variable }\end{array}$ & B & $\begin{array}{l}\text { Std. } \\
\text { Error }\end{array}$ & $\beta$ & $t$ & $p$ \\
\hline \multirow{4}{*}{$\begin{array}{c}\text { Text } 1 \\
\text { Vocalized } \\
\text { Reading } \\
\text { Comprehens } \\
\text { ion }\end{array}$} & \multirow[b]{2}{*}{.394} & \multirow[b]{2}{*}{.155} & \multirow[b]{2}{*}{.092} & \multirow[b]{2}{*}{2.478} & \multirow{2}{*}{$\begin{array}{c}.10 \\
3\end{array}$} & $\begin{array}{l}\text { Reading accuracy } \\
\text { - Words with short } \\
\text { vowels }\end{array}$ & -.228 & .151 & -.445 & -1.506 & .144 \\
\hline & & & & & & $\begin{array}{l}\text { Reading accuracy } \\
\text { - Words without } \\
\text { short vowels }\end{array}$ & .333 & .152 & .647 & 2.187 & .038 \\
\hline & \multirow[b]{2}{*}{.145} & \multirow[b]{2}{*}{.021} & \multirow[b]{2}{*}{-.051} & \multirow[b]{2}{*}{.290} & \multirow[b]{2}{*}{$\begin{array}{c}.75 \\
0\end{array}$} & $\begin{array}{l}\text { Fluency- Words } \\
\text { with short vowels }\end{array}$ & $2 . \overline{047}$ & 3.182 & -.125 & -.643 & .526 \\
\hline & & & & & & $\begin{array}{l}\text { Fluency - Words } \\
\text { without short } \\
\text { vowels }\end{array}$ & 3.951 & 7.385 & .104 & .535 & .597 \\
\hline $\begin{array}{l}\text { Text } 2 \\
\text { Vocalized } \\
\text { Reading }\end{array}$ & .301 & .091 & .024 & 1.349 & $\begin{array}{l}.27 \\
6\end{array}$ & $\begin{array}{l}\text { Reading accuracy- } \\
\text { Words with short } \\
\text { vowels }\end{array}$ & .061 & .190 & .099 & .323 & .749 \\
\hline
\end{tabular}




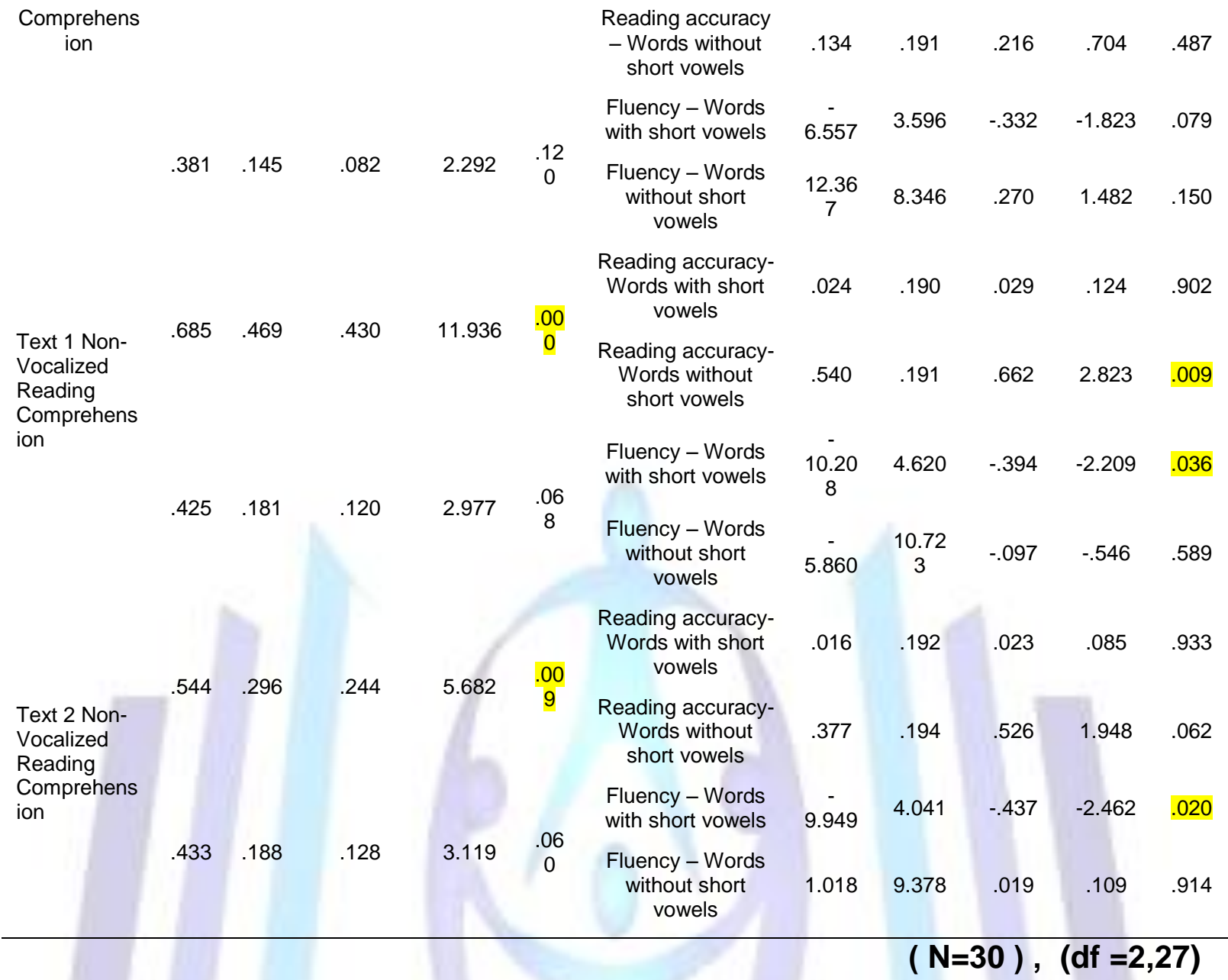

\section{Discussion}

Our findings show that the addition short vowels in Arabic texts helped the reader in reading comprehension, reading accuracy and reading fluency in every group, whether regular or weak in reading abilities.

We can also say that this finding has direct implications for each of the research assumptions, meaning an improvement in reading accuracy and fluency abilities, allowing us to predict reading comprehension levels, which can certainly be important learning aid in education in general, and reading skills in particular. With the addition of other factors, and as Abu Rabia's research has revealed, especially context, reading accuracy, fluency and comprehension are greatly improved. This is what Abu-Rabia described as "a function of a parallel combination of interactive-dynamic processing for identifying words and influences on sentence contexts." That is to say, the vocalization and context complement one another and allow the reader to use reading skills and power of thinking to connect the context of the text with the right word, with "confirmation" being provided by the vocalization of that word/sentence. In other words, when both context and short vowels are present, it is almost impossible to err in pronunciation, meaning or in overall reading comprehension. Even more so, in cases of certain doubt (like among younger and/or weaker readers) regarding context, the vocalized word will lead to a greater understanding of the context and meaning of the text. Therefore, the short vowels and vocalization lead to broader cognitive process where the reader must utilize his reading abilities on every level, not only for pronunciation, but also for understanding the word/sentence and entire text (Abu Rabia, 1998). No less important, however, is the fact that among regular and skilled readers as well, vocalization helped. The fact that a skilled reader already reads even without short vowels in full and proper comprehension does not mean that he cannot improve their reading accuracy and skills, as was found in the relevant studies conducted among more skilled and capable adult readers. As for weak readers, the short vowels become a real key for the correct pronunciation of a word, sentence or text (Abu Rabia, 1997a, 138). As for normal or more skilled readers, though perhaps not being as critical for helping in basic recognition and proper pronunciation of words and texts, short vowels can be a stimulus and supplementary tool for improvement even already well-honed skills. It might even be argued that normal and more skilled readers may be helped by short vowels even more than weaker readers, because they begin on a higher reading level at the outset, so their improvements may be also proportionally more significant.

As for an additional point suggested by assumption 3, meaning that one can predict reading comprehension levels from reader fluency/word processing, this idea also receives significant support in our findings, because the moment one can identify and understand an individual word thanks to short vowels, it is only natural that reading and understanding the text 
will be easier. Besides, the very presence of the short vowels, which prevents any other possible interpretation, the reader will have to use other "help aids" much less, like context, which may lengthen the thinking and decoding process of the word/sentence. Further, when an isolated word is presented without context in Arabic, only the more skilled reader will more easily identity it, either because of past experience or by logical thinking abilities, as found by Abu Rabia (1996), Baluch and Besner (1991) and Shimron (1989, 1997).

Since so many research studies in Arabic have found that the use of short vowels in texts significantly improves reading accuracy, comprehension and fluency for virtually all ages and reading-skill levels, we have found the most important and unequivocal method for the acquisition of reading skills and reading comprehension in Arabic for every age and every situation. The very motivation of many of the studies conducted on this topic focuses on finding ways and methods to improve reading and literacy abilities of children in general, and in the Arab sector in particular, since the importance of reading skills is self-evident in any society. Further, the more these skills are encouraged and developed at the youngest ages possible, academic, social, cultural and economic achievements continue to improve. Since the Arabic language presents special challenges because of its very essence and distinction from other Semitic languages, like Hebrew, educators and educational researchers are always searching for efficient solutions to improve reading skills and reading comprehension among Arabic speaking children everywhere in the world. Therefore, despite the significant and proven contribution of vocalization in Arabic writing, this finding must be carefully analyzed against a wide range of other conditions, age groups, learning deficiency levels and more, just as a significant number of researchers suggest, like Baluch and Besner (1991), Berent and Berfetti (1995), Goodman (1967) and others. Even in the sphere of this study, one cannot relate too high significance to the unequivocal and significant findings regarding the importance and efficacy of short vowels in learning to read Arabic, but rather correlate these findings in the field and gain maximal benefit for each and every group while examining other factors that influence the acquisition of reading skills among the Arab-speaking public.

The research findings point to the fact that short vowels have an impact on reading comprehension in each of the two groups that participated in the study. An analysis of the findings reveals a significant difference in reading comprehension of a vocalized text no. 1 among both weak and regular readers. The same results were discovered in reading text no. 2 in terms of reading comprehension, reading accuracy and reading fluency also without short vowels. Significant differences were found in all categories, whether the texts were vocalized or not.

In addition, the research findings show that vocalization does indeed contribute significantly to both weak and norma readers, meaning that short vowels significantly improved reading comprehension of these readers. Moreover, the substantial difference between reading comprehension among weaker versus normal readers is directly related to the text type (vocalized/un-vocalized)

\section{References}

1 Abu-Rabia, S. (1995) . Learning to read in Arabia . Reading Psychology , 16 , 351- 394

2 Abu- Rabia, S. (1999). The effect of Arabic Short vowels on reading comprehension. Journal of Psycholinguistic Research , 28 , 93-101n

3 Abu- Rabia , S. (2001). The role of short vowels in reading Semitic scripts. Reading and Writing , 14 , 39- 59

4 Abu-Rabia, S. (1995). Learning to read in Arabic: reading, syntactic, orthographic, \& working memory skills in normally achieving \& poor Arabic readers, Reading Psychology: An international Quarterly, 16, 351-394.

5 Abu-Rabia, S. (1996). The role of short vowels \& context in the reading of highly skilled Arabic readers. Journal of Psycholinguistic Research, 26,629-641.

6 Abu-Rabia, S. (1997a). The need for cross-cultural considerations in reading theory: The effects of Arabic sentence context in skilled \& poor readers, Journal of Research in Reading,20,137-147.

7 Abu-Rabia, S. (1997b). Reading in Arabic orthography: The effect of short vowels \& context on reading accuracy of poor \& skilled native Arabic readers in reading paragraphs, sentences, \& isolated words, Journal of Psycholinguistic Research, 26, 465-482.

8 Abu-Rabia, S. (1997c). Reading in Arabic orthography: The effect of short vowels \& context on reading accuracy of poor \& skilled native Arabic readers. Reading \& Writing: An Interdisciplinary Journal, 9, 65-78.

9 Abu-Rabia, S. (1998). Reading Arabic texts: Effects of text type, reader type \& vowelization. Reading \& Writing : An Interdisciplinary Journal, 10, 105-119.

10 Abu-Rabia, S. (1999). The effect of Arabic short vowels on the reading comprehension of second- \& sixth-grade native Arab children. Journal of Psycholinguistic Research, 28, 93-101.

11 Abu-Rabia, S. (2001). The role of short vowels in reading Semitic scripts: Data from Arabic \& Hebrew. Reading \& Writing: An Interdisciplinary Journal, 14, 39-59.

12 Abu-Rabia, S. (2002). Reading in a root-based morphology language: the case of Arabic. Journal of Research in Arabic, 25, 299-309.

13 Abu-Rabia, S. (2007).The role of morphology \& short vowelization in Reading Arabic of normal \& dyslexic readers in 
Grades 3, 6, 9, \& 12, Journal of Psycholinguistic Research, 36, 89-106.

14 Abu- Rabia, S . (1996a). Attitude and cultural background and their relationship to reading comprehension in a second language: A comparison of three social contexts, International Journal of Applied Linguistics , 6 , 81-107.

15 Abu- Rabia, S . (1998). Reading Arabic texts: Effect of type, reading type and vowelization, Reading and Writing : An Interdisciplinary Journal , 10 , 105-119.

16 Abu- Rabia , S (1998a). Attitudes and culture in second language learning among Israeli- Arab students, Curriculum and Teaching , $13,12-30$.

17 Abu-Rabia, S., \& Saliba, F. (2008). The role of roots \& phonological patterns in reading Arabic among dyslexic \& normal native Arabic readers, Australian Journal of Learning Difficulties, 13, 115- 144.

18 Abu-Rabia, S., \& Siegel, L. (1995), Different orthographies, different context effects: The effects of Arabic sentence context in skilled \& poor readers,. Reading Psychology: An international Quarterly, 16. 1-19.

19 Abu- Rabia, S , Siegel , L . (2003).Reading skills in three orthographics: The case of trilingual Arabic-Hebrew- Englishspeaking Arabic children, Reading and Writing , 16, 611- 634.

20 Abu-Rabia, S., Siegel, L. (2002). Reading syntactic, orthographic \& working memory skills of bilingual Arabic- English speaking Canadian children, Journal of Psycholinguistic Research, 31, 661-678.

21 Abu-Rabia, S., \& Taha, H. (2006). Phonological errors predominate in Arabic spelling across grades 1 to 9, Journal of Psycholinguistic Research, 35, 167- 188.

22 Baluch, B. \& Besner, D. (1991). Visual word recognition: Evidence for strategic control of lexical \& non lexical routines in oral reading,. Journal of Experimental Psychology, Learning, Memory \& Cognition, 17, 644-652.

23 Berent, I. \& Berfetti, C. (1995). A rose is a REEZ: The two-cycles model of phonology assembly in reading English, Psychological Review, 102, 146-184.

24 Berfetti, c ., \& Rieben, L.(1991). Learning to Read, New Jersey : Lawrence Erlbaum Associates, Inc .

25 Frost, R., Bentin, S. (1992a). Processing phonological \& Semantic ambiguity: Evidence from Semantic priming at different SOAs, Journal of Experimental Psychology, Learning. Memory, \& Cognition, 18. 58-68.

26 Frost, R, Bentin,S . (1992b). Reading consonants \& guessing short vowels; Visual word recognition in Hebrew orthography, In R . Frost \& L . Katz (Eds.) Orthography, Phonology, Morphology. \& Meaning, (pp.27-44), North-Holl \& Amsterdam.

27 Goodman, K. ( 1967). Reading: A psycholinguistic guessing game, Journal of the Reading Specialist, May, $497-508$.

28 Person , U . (1994). Reading for understanding: An empirical contribution to the metacognition of reading comprehension. Linkoping Studies in Education Psychology Dissertations, 41, Sweden: Linkoping University,

29 Ravid, D. , \& Shlesinger, Y. (2001). Vowel reduction in modern Hebrew, Falia Linguistica, 35 , 371 - 397.

30 Ravid, D, Shlesinger, Y. (2001). Vowel reduction in modern Hebrew: Traces of the past and current variation. Falia Linguistica, 35, 3-4 , 371-397.

31 Shimron, J. (1993). The role of short vowels in reading: a review of studies of English \& Hebrew, Psychological Bulletin, 114, 52-67.

32 Shimron, J., \& Sivan,T. (1994) Reading proficiency \& orthography: Evidence from Hebrew \& English, Language Learning, 44, 5-27.

33 Shimron, J . (1999). The role of vowel signs in Hebrew: Beyond word recognition, Reading and Writing: An Interdisciplinary Journal , 11 , 301-319.

34 Shimron, J . \& Sivan, T. (1994). Reading proficiency and orthography: Evidence from Hebrew and English Language Learning, 44, 5-27. 